\title{
BMJ Open 'Food for Life and Palliation (FLiP)': a qualitative study for understanding and empowering dignity and identity for terminally ill patients in Asia
}

\author{
Paul Victor Patinadan (D) , ${ }^{1}$ Geraldine Tan-Ho, ${ }^{1}$ Ping Ying Choo, ${ }^{1}$ \\ Casuarine Xinyi Low, ${ }^{2}$ Andy Hau Yan Ho (D) ${ }^{1,3,4}$
}

To cite: Patinadan PV, Tan-Ho G, Choo PY, et al. 'Food for Life and Palliation (FLiP)': a qualitative study for understanding and empowering dignity and identity for terminally ill patients in Asia. BMJ Open 2021;11:e038914. doi:10.1136/ bmjopen-2020-038914

- Prepublication history for this paper is available online. To view these files, please visit the journal online (http://dx.doi org/10.1136/bmjopen-2020038914).

Received 30 March 2020 Revised 18 March 2021 Accepted 28 March 2021

A Check for updates

(c) Author(s) (or their employer(s)) 2021. Re-use permitted under CC BY-NC. No commercial re-use. See rights and permissions. Published by BMJ.

${ }^{1}$ Psychology, Nanyang Technological University, Singapore

${ }^{2}$ Health Services and Systems Research, Duke-NUS Medical School, Singapore

${ }^{3}$ Lee Kong Chian School of Medicine, Nanyang Technological University, Singapore

${ }^{4}$ The Palliative Care Centre for Excellence in Education and Research (PaIC), Singapore

Correspondence to Dr Andy Hau Yan Ho; andyhyho@ntu.edu.sg

\section{ABSTRACT}

Objectives With 'eating' posited as Singapore's domestic pastime, food experiences for Singaporeans constitute national, social, ethnic and personal identities. However, though they form significant parts of Singaporean existence across the lifespan, studies and observations about food experiences for individuals at the end of life remain noticeably absent. Extant literature continues to focus on nutritional practice during illness and the active dying process, forgoing the rich lived experiences of food in the lives of patients and their families. The current work sought to qualitatively extricate through a constructivist phenomenological approach, the 'food voices' of Singaporean palliative care patients and their families. It also simultaneously aimed to assess the role of food in bolstering their subjective feelings of dignity and identity, while also considering resultant clinical implications.

Setting Homes of patients within the Singaporean palliative care setting.

Participants A subset of qualitative data $(n=25)$ in the form of dyadic interviews with terminally ill patients and a family caregiver was generated from a larger family dignity intervention study that explored the experience of living and dying among Asian palliative care patients and their families.

Results Framework analysis with both inductive and deductive approaches informed by the a priori domain of food resulted in the generation of four major themes, each with three subthemes. These were organised into the Food for Life and Palliation model. They include: (1) feeding identity and familial bonds, (2) liminal subsistence in illness transition, (3) food becoming lineage, and (4) compassionate nourishment.

Conclusions Clinical implications are considered; including food-focused interventions that enhance dignity, promote meaning-making and facilitate legacy construction. Developmental suggestions are also directed at industry partners producing end-of-life nutrition products.

\section{INTRODUCTION}

Nutritional assimilation is unarguably an intrinsic aspect of the human condition. Unlike the automatic, continuous and unconscious process of breathing, eating develops
Strengths and limitations of this study

Novel, first-of-its-kind study that considers the multifaceted food experiences of individuals at the end of life.

- Practices a rigorous methodology and upholds the highest standards of qualitative research.

- Showcases a robust qualitative model that can easily be applied to clinical interventions for holistic care of patients at the end of life.

- Lack of directed query considering the domain of food towards participants.

- Not all racial demographics in Singapore's cohesive multicultural society were represented due to sampling issues.

from compulsory communal dependence. ${ }^{1}$ From initial nursing to meal preparation in childhood, we require the constant presence and action of others to initiate these food experiences at regular intervals. Such intimacy, that is, teat to mouth, spoonfeeding interactions and being present tableside, lays the groundwork for the development of strong feelings about food and drink. ${ }^{1}$ Researchers have observed how food represents far more than mere sustenance to most. ${ }^{2}$ Lupton $^{3}$ extensively considered the role of food in our emotional lives; describing how anger, anxiety, caring, disappointment, disgust, embarrassment, frustration, guilt, happiness, hate, love, nostalgia, resentment, revulsion, security and comfort associate with food-based experiences. She perhaps most eloquently observed that 'appetite is an emotionally flavoured hunger... (that) humans' relationship with food and eating are subject to the most powerful emotions experienced in any context'. ${ }^{3}$ Food also constitutes to the formation of family identity and domestic life, with familial food experiences socialising moral values, duties 
and valued experiences. ${ }^{4}$ Home-made foods and shared consumption practices construct 'the home' and even connect families to duties of care ${ }^{56}$ So fundamental is the relationship between food, culture, tradition and personal identity that the interdisciplinary field of 'foodways research' evolved to offer a means for academic investigation of this phenomenal process.

Within the larger sociological perspective of symbolic interactionism, food is seen to be a crucial social product that allows for the provision of meaning through interpretation, with people practising selection, sourcing and agency when eating. ${ }^{7}$ It is seen as a nexus of social interaction, serving as a means of identification and value formation within individuals and groups. ${ }^{8}$ Food is also observed to colour one's everyday cultural and psychological lives through the formation of eating preferences, meal habits and rituals. ${ }^{9}$ Often, the medium connects participants of these food rituals to cultural norms and values. ${ }^{10}$ Hauck-Lawson ${ }^{8}$ coined the term 'food voice' to encapsulate this powerful channel for the expression of numerous subjective, cultural and personal meanings; how food experiences are thought about and expressed. The author discusses how when a person chooses (or does not choose) what to procure, prepare and eat, they make commanding statements about their identity and culture. Long ${ }^{11}$ further elaborated that akin to fashion, hairstyles or music, these food forms through food voice are an accepted identity-centred medium of communication. The choice to remain vegetarian in the presence of those eating meat, for example, demonstrates a particular food voice entrenched in a value-based system. ${ }^{11}$ Researchers have navigated various psychosociocultural phenomena by attending to food voices, including ethnicity and heritage, ${ }^{11}$ gender dynamics, ${ }^{12}$ faith and spirituality ${ }^{13}$ and even issues of institutionalised power. ${ }^{14}$ Food voices, as such, can provide a holistic representation of the human experience when considered in tandem with the spoken or written voice.

\section{Food identity in Singapore: a uniquely local experience}

Singapore is a small South-East Asian city state that gained independence from British colonial rule in 1965. A busy port of call during its colonial trading years, early arrivals into Singapore brought from their respective mainland their own local cuisines. Tossed into the veritable melting pot of the fledgling country were the native vegetables and seafood favoured by Indian settlers, the strict, codified diets of Malay Muslims from the surrounding archipelago, the myriad cooking styles of the various Chinese clans as well as numerous Western influences. ${ }^{15}$ The iconic Peranakan dish of laksa, a spicy seafood noodle dish in rich coconut gravy, is seen to draw from Chinese, Malay, South Indian and Eurasian influences. ${ }^{16}$

Eating in Singapore is, unsurprisingly, seen as a national passion, with a former Minister of Trade and Industry stating that we 'spend a lot of time eating and thinking about food. Even when we are eating, we are already thinking about the next meal. It is an inseparable part of our culture'. ${ }^{17}$ Strong opinions of food exist in the Singaporean psyche, with citizens being fiercely protective of iconic Singaporean dishes. Social media exchanges in recent years, for example, have seen Singaporeans in heated online arguments with citizens from other SouthEast Asian countries about the origin or preparation of their favourite foods. ${ }^{18}$ The antiquated habit of asking if one has eaten remains a polite and appreciated greeting, even in contemporary society. ${ }^{15}$

Perhaps the complexities of Singaporean national identity are best expressed on a plate. Other than being a unifying force with regard to nationhood, food experiences additionally provide a marker for ethnic identity within the country's mixed-race society. ${ }^{19}$ Suen $^{20}$ emphasises that food remains 'one of the strongest ways' in which ethnic groups 'articulate their memories', with the cooking and consumption of certain traditional dishes being a means to sustain an affiliation even through weak or weakening ties. Though the cuisine of ancestral cultures tends to transform over time, mostly due to convenience ${ }^{15}$ the value of their origin and linkages to deeprooted feelings of heritage are evident and celebrated.

Food experiences remain an integral and encompassing facet in the daily lives of Singaporeans; forming personal, familial, cultural and shared national identities. Though this coalescent 'food identity' is persistent across an individual's development and lifespan, little is observed or understood with regard to its expression within the endof-life context.

\section{Dying and the silencing of food voice}

Extant local literature, research and academic inquiry seem to parallel international trends; in that studies on nutritional assimilation at the end of life focus on practical feeding during illness trajectories and the active dying process, ethical decision-making about nutritional withdrawal during dying, anorexia and medicalised nutritional goals. ${ }^{21-24}$ Rarely do studies consider the accrued meaning of food experiences, and when they do, it is usually within similar acute contexts. ${ }^{25}{ }^{26}$ Though Wong and Krishna ${ }^{25}$ posit several important primary themes in their Singaporean case observations (reassurance, filial piety, balancing competing goals and maintaining normalcy), their small sample $(n=4)$ and chosen methodology make it difficult to generalise assumptions. As such, the rich, lived and continuing experience of food in the lives of patients and their families is forgone within current academic efforts. Kaplan ${ }^{27}$ observes that the complexity of food activities yields information about creativity, function, traditionality, variation, change and continuity. These are all empowering conceptions and practice that are especially salient for dying individuals, allowing them a measure of dignity in their final days.

From the development of the empirical model of dignity-conserving care, ${ }^{28}$ Chochinov $^{28}$ observed that undermining dignity is strongly associated with depression, hopelessness, instances of anxiety, loss of will to live, a desire for death, feeling of being a burden on others 
and an overall poorer quality of life. Studies have shown that a loss of dignity, meaning and feelings of being a burden unto others link to requests for a hastened death, with the eventual ramifications of these feelings leading to increased rates of suicide. ${ }^{29}$ Spiritual peace, relieving burden and strengthening relationships with loved ones, however, are among the most imperative facets of death with dignity. ${ }^{30}$

Within the Asian context, Ho $e t a \ell^{11}$ forward the patient family model of dignified care, constructed after investigating the perspectives terminally ill older Asian Chinese patients and their family members had about the constitution of dignity. The researchers enunciated the need for (1) spiritual plasticity; helping patients find meaning in their pain, letting go of attachments, attaining moral transcendence with the love and support of their family caregiver, (2) family connectedness via creation of a platform for expressing appreciation, achieving reconciliation, fulfilling family obligations and establishing continuing bonds with their descendants, (3) family integrity, as well as (4) filial compassion that involves the mutual support, reciprocal relationship, emotional connection and altruistic reverence gained through open communications and exchanges with their loved ones. ${ }^{31}$ There is much potential for the empowering 'food voice' of Hauck-Lawson ${ }^{8}$ to create meaning, establish a platform for communication and provide the support needed for Asian palliative care patients in increasing their dignity at such a critical juncture, as per the work of Ho et al. ${ }^{31}$ Hauck-Lawson ${ }^{8}$ enunciates that the food voice can reveal aspects of one's life not commonly seen, lending pragmatic information and insight for clinical practice. However, this food voice, nourished over the course of a lifetime and laden with multifaceted significance, is reduced to a barely audible whisper in the palliative care context. To the best knowledge of the author, there currently exists no study that maps the food-related identity, continuing role of food and food experiences or memories of dying individuals and their families. The current work addresses this research gap and sought to qualitatively extricate through a constructivist phenomenological approach, the food voices of Singaporean palliative care patients and their families. It also simultaneously aimed to assess the role of food in bolstering their speakers' subjective feelings of dignity and identity, and consider the resultant clinical implications.

\section{METHODS}

The following study draws a subset of qualitative dyadic interview data $(n=25)$ from a larger randomised controlled trial for a novel family dignity intervention (FDI) for Asian palliative care patients and their families $(n=50)$. Table 1 showcases participant demographic data for the current sample. The complete sampling methods, inclusion criteria, interview procedure and comprehensive study protocol are described in greater detail within a separate publication. ${ }^{32}$ Briefly, the FDI was conceptualised

\begin{tabular}{|c|c|c|}
\hline Dyad code & Age (years) & Sex \\
\hline $\mathrm{P} 1 / \mathrm{FC} 1$ & $64 / 55$ & $\mathrm{~F} / \mathrm{F}$ \\
\hline P2/FC2 & $70 / 38$ & $\mathrm{~F} / \mathrm{F}$ \\
\hline P3/FC3 & $60 / 58$ & $\mathrm{M} / \mathrm{F}$ \\
\hline $\mathrm{P} 4 / \mathrm{FC} 4$ & $69 / 35$ & $\mathrm{~F} / \mathrm{F}$ \\
\hline P5/FC5 & $85 / 52$ & $\mathrm{~F} / \mathrm{M}$ \\
\hline P6/FC6 & $77 / 69$ & $\mathrm{M} / \mathrm{F}$ \\
\hline P7/FC7 & $79 / 79$ & $\mathrm{M} / \mathrm{F}$ \\
\hline P8/FC8 & $80 / 75$ & $\mathrm{M} / \mathrm{F}$ \\
\hline P9/FC9 & $86 / 63$ & $\mathrm{M} / \mathrm{F}$ \\
\hline P10/FC10 & $91 / 57$ & $\mathrm{~F} / \mathrm{M}$ \\
\hline $\mathrm{P} 11 / \mathrm{FC} 11$ & $81 / 45$ & $\mathrm{M} / \mathrm{F}$ \\
\hline $\mathrm{P} 12 / \mathrm{FC} 12$ & $55 / 20$ & $\mathrm{M} / \mathrm{M}$ \\
\hline $\mathrm{P} 13 / \mathrm{FC} 13$ & $74 / 70$ & $\mathrm{M} / \mathrm{F}$ \\
\hline P14/FC14 & $63 / 68$ & $\mathrm{~F} / \mathrm{M}$ \\
\hline P15/FC15 & $88 / 82$ & $\mathrm{M} / \mathrm{F}$ \\
\hline P16/FC16 & $58 / 44$ & $\mathrm{M} / \mathrm{F}$ \\
\hline P17/FC17 & $64 / 61$ & $\mathrm{M} / \mathrm{F}$ \\
\hline P18/FC18 & $58 / 29$ & $\mathrm{~F} / \mathrm{F}$ \\
\hline P19/FC19 & $80 / 47$ & $\mathrm{M} / \mathrm{F}$ \\
\hline P20/FC20 & $55 / 23$ & $\mathrm{~F} / \mathrm{F}$ \\
\hline P21/FC21 & $65 / 45$ & $\mathrm{M} / \mathrm{F}$ \\
\hline P22/FC22 & $83 / 53$ & $\mathrm{M} / \mathrm{F}$ \\
\hline P23/FC23 & $58 / 48$ & $\mathrm{M} / \mathrm{F}$ \\
\hline P24/FC24 & $60 / 59$ & $\mathrm{M} / \mathrm{F}$ \\
\hline P25/FC25 & $73 / 51$ & $\mathrm{M} / \mathrm{F}$ \\
\hline
\end{tabular}

F, female; FC, family caregiver participants; M, male; P, patient participants.

from empirical findings surrounding the subjective experience of dignity in Asian and Western contexts. ${ }^{28} 31$ The intervention integrates narrative life review, reminiscence and logotherapeutic methods to provide psychosociospiritual support to patients facing the end of life as well as their families. It was piloted for acceptability and feasibility before being fully adapted into the larger intervention study. The FDI itself comprises an audio-recorded dyadic semistructured interview with a patient and a family caregiver conducted in their homes. The family caregivers were commonly spouses, children or siblings of the patient. Dyads were recruited through the local inpatient, day care and homecare hospice service units of HCA Hospice Care, Dover Park Hospice, Tan Tock Seng Hospital, Singapore Cancer Society and Methodist Welfare Services. Patients were included in the larger study if they were above 50 years of age with a prognosis of less than 12 months due to a life-limiting illness, receiving palliative care and in good cognitive health. Family caregivers were included if they were identified by patients to 
be their main caregivers, were above 21 years of age and had no major mental health issues.

In conducting the intervention, the FDI therapist uses a guided question framework to facilitate joint conversation on shared memories and living wisdoms that lead to meaning-making and the expression of appreciation and reconciliation. Questions centred on favourite memories, life lessons learnt, appreciation for their loved ones and hopes and dreams for the future. This is done with the ultimate goal of creating a legacy document that tells the life story of the patient; and is bestowed to the rest of the family through an open reading exercise. Each interview lasted between 60 and $90 \mathrm{~min}$ and was conducted in English, Malay, Mandarin or a Chinese dialect (Hokkien, Teochew or Cantonese). These recorded interviews were transcribed verbatim, translated into English by a native language speaker where applicable and edited into legacy documents. Transcripts and legacy documents were reviewed and finalised by patients and caregivers to ensure accuracy and authenticity. The Standards for Reporting Qualitative Research guidelines ${ }^{33}$ were duly followed in the reporting of this study.

\section{Research design and procedure}

The study adopted a constructivist phenomenological research paradigm, which enabled co-construction of participant dyads' food voices and experiences into a holistic perspective. The co-constructive paradigm of this study ensured transferability, whereby findings may apply to other settings, especially those of shared cultural norms, values and have similarity of physical experiences. With Singapore being the defining confluence point of a multicultural Asia, ${ }^{15}$ the country can be a key representative reference for other Asian societies. Two members of the research team thoroughly went through all 50 transcripts of the larger FDI study and selected 25 that were the richest with food-based information, allowing for inter-rater concordance and research rigour.

\section{Patient and public involvement}

The current study employed a patient-centred approach to identify the food experiences, and capture the food voices of terminally ill Singaporean patients. However, patients were not involved in the design, conduct, reporting or dissemination plans of this study, acting only as participants. Likewise, the public were not involved in the mentioned processes.

\section{Data analysis}

All audio recordings were transcribed with the aid of the Express Scribe software and imported into QSR NVivo V.12 for analysis. Under the lens of the identified larger domain of food, framework analysis employing inductive and deductive approaches was conducted through open, selective and axial coding, with a focus on the generation of common themes among the transcripts. At every step, codes were methodologically assessed and reassessed for importance and accuracy by the research team. This allowed for the identification, analysis and reporting of patterns and themes which emerged within the data. ${ }^{34}$ These themes represent a patterned response or meaning within the data set, capturing an important aspect of the data in relation to the research objectives. The themes were then organised into a thematic framework, which allowed the classification and observance of interactions and thematic relationships, resulting in a working model. Research rigour and trustworthiness of findings were ensured by adopting stringent methodological approaches including maintenance of an audit trail, peer debriefing, checking preliminary themes and interpretations against data obtained in subsequent interviews, inter-researcher consensus in finalising of themes, achievement of data saturation and theory triangulation. Researcher reflexivity was also developed through maintenance of a shared team journal and affordances for open and honest dialogue between members throughout the study timeframe. ${ }^{35} 36$

\section{RESULTS}

Figure 1 showcases the four major themes and 12 subthemes generated from the data, organised into the Food for Life and Palliation (FLiP) model. These themes include food experiences and memories surrounding the self and family during a life of normalcy (feeding identity and familial bonds), the changing nature of food roles and occurrences from the onset of terminal illness and through the illness trajectory (liminal subsistence in illness transition), the continuing transmutation of food identity and its coalescence into social and personal legacy (food becoming lineage) and the enduring nature of food as an expression of care (compassionate nourishment). The themes are described in greater detail below and illustrated with direct quotes from participants.

\section{Feeding identity and familial bonds (number of transcripts theme has appeared in; $n=24$ )}

Participants stressed the role of food in the formation of their identity and sense of personhood, as well as a primary means of familial bonding during the course of their lives before illness onset. These included finding their food voice, as well as significant positive and negative food-related memories, seen within the subthemes of (1) food and self-definition, (2) fond food memories, and (3) hardship, going hungry and feeding resilience.

\section{Food and self-definition $(n=12)$}

In true Singaporean fashion, participants regarded food as a major aspect of their personhood and identity, with a resonant food voice emerging from a young age.

I love to eat. I love mee kuah [Southeast Asian noodle soup]. I can eat two bowls. When children finish the first bowl last time, they would not dare to ask for another, choosing to sit quietly. Then, my mother would say, 'Ah, this one, (I'm) sure she wants another bowl!' I will always go for a second bowl. I'm the only one in 


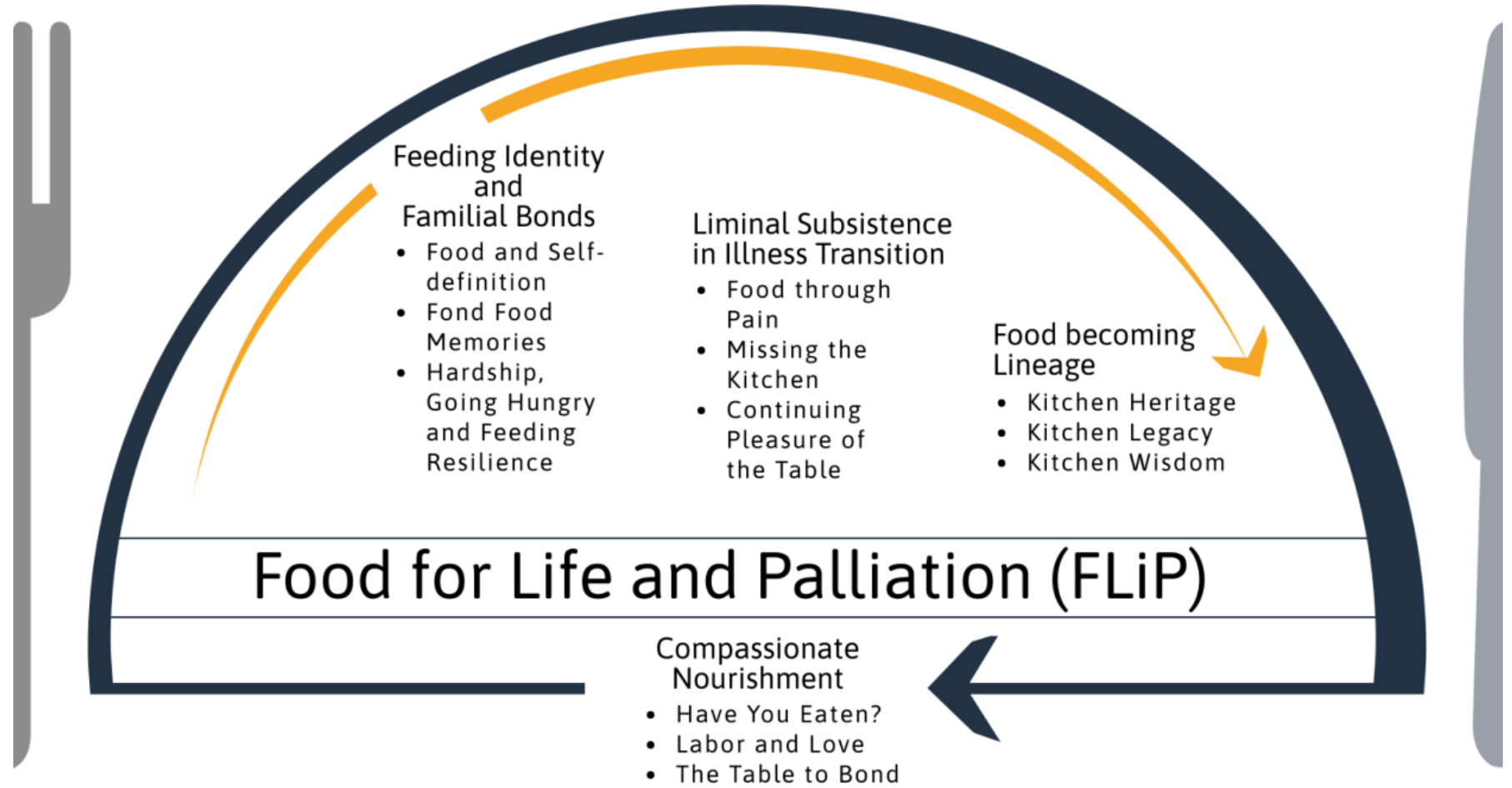

Figure 1 : The Food for Life and Palliation qualitative model.

the family who, you know, loves to eat... kuat makan $a h$ ! [Malay: Being a big eater]. People would take one bowl, I (would) take two. (Female patient in her 50s)

Similarly, this food-centric self-definition would also extend to the formation of familial identity; what defined the home and those who lived in it.

We love to eat. There's so much to eat, (one minute) we're eating glass noodles, the next we're eating tapioca noodles and whatnot. It's just a variety (for us) ... (even) the helper said, 'This family of yours is always cooking, cooking, cooking, and eating, eating, eating.' (Female patient in her 50s)

\section{Fond food memories $(n=18)$}

Participant dialogue was rich with joyful food-related memories, many of which were defining points in different aspects of their lives. The following participant expressed this sentiment with regard to his food experiences during his vocation.

(Participant on his work within a busy international port) '[They would say] Take whatever you want, put it in a plastic bag, take it away.' It's fresh food you know! Fruits...chicken legs, some cold cuts; ham? And the food was really like from a hotel. So, we looked forward to that. Some of the food we didn't understand how to eat. The first time I ate, what do they call it, 'caviar'? I didn't like it. Didn't understand it, didn't like it. Later on, after years, I got used to it. As I got older, I got more comfortable eating these things. I learned how to eat...oysters? Very nice time I had, beautiful. (Male patient in his 70s)
Food experiences during festivals and ethnic celebrations also feature prominently as positive and memorable life events often spent with family and the wider community.

During Hari Raya [Islamic Festive Season], even though we didn't know how to tie the wrapping for the ketupat [traditional Malay ricecake dish], we would just [haphazardly] do it. Even up till now, we are still talking about the peanuts. We would buy many kilograms of them, and would have to peel the skin off each peanut individually by popping them between our fingers. Being children, we would play with them; 'pop, pop, pop-ing!' them at each other. We would get scolded, but it was so much fun. (Female caregiver in her $50 \mathrm{~s}$ )

Hardship, going hungry and feeding resilience $(n=17)$

Many older participants had lived through Singapore's occupation of foreign powers during World War II. Poverty, hardship and difficulty at simply securing a meal made for tough but vital lessons in building resilience and adaptability enough to weather life's harsh conditions.

During that period, each household would cordon off a portion in front of their house and say, 'Okay, this is my plot of land.' And so, each family, would try their best to plant whatever food that we could for daily consumption. We had tapioca, sweet potato, chillies...these 'food' trees. So...we had to make do like that. Sometimes, we got ration cards. So, we got a little bit of rations... and that was how we survived during those times. Some families, the more 
resourceful ones maybe? They turned to hawkering. For my family that time, I have no idea of how we managed to get an income really... (Male patient in his $80 \mathrm{~s}$ )

These commonplace scenarios were also used as lessons in appreciating the ease and convenience of modern times.

I climb the coconut trees often to pick coconuts. The coconuts didn't belong to us, they belonged to the landowner. We were actually stealing the coconuts for our consumption, because we couldn't afford much food. It was a normal occurrence. You are very lucky that you never had to go through these experiences. You have been well fed and well clothed since you were born. (Male caregiver in his 50s)

\section{Liminal subsistence in illness transition $(n=19)$}

The following themes highlight the changing nature of participants' relationship with food at the onset of terminal illness. Rich food experiences are seen to fall to the wayside, with nutritional assimilation generally becoming a means of subsistence and survival, but on some occasions, serving as the smallest possible means of pleasure during a state of betweenness. These are observed in the subthemes of (4) food through pain, (5) missing the kitchen, and the (6) continuing pleasure of the table.

\section{Food through pain $(n=15)$}

The formerly variegated and flavourful food experiences that patients experienced during their healthy life course begin to dull and grey, with nutritional requirements and restrictions due to illness curtailing their experiences.

[In the past], I used to like to eat all the different types of hot, spicy, curried food and all that. But now because of this particular cancer problem, I can't quite eat those foods, and I can't eat the amount I used to eat before. At one point, it was just porridge, porridge, porridge. (Male patient in his 70s)

This transitory food state that patient participants now live in also places pressure on family members, forcing them to reorganise perspectives, habits and formerly shared experiences.

To be honest, I'm still buying junk food too. Prior to my father falling sick, I would often drink Coca Cola; he would join me and we would drink Coca Cola together. However, we have stopped doing that ever since he was diagnosed with his illness... his stomach has become acidic as a result of his smoking habit as well, and he constantly craves for something sweet. My father is struggling to quit drinking Coca Cola as he is constantly thirsty. (Female caregiver in her 20s)
Missing the kitchen $(n=4)$

This subtheme holds a level of specificity and was not observed in many participant dialogues. However, it remains especially significant for patients who consider the practice of culinary skills an important facet of their autonomy.

Now I don't cook, I can't. Unless it's something simple, otherwise I can't stand for too long, I'll get tired. I can't stand for long, as my legs are weak, so cooking in the kitchen is not good for me. (Male patient in his $70 \mathrm{~s})$

Not being able to practise their craft is observed to cause additional psychosocial distress, above the physical demands and worsening of their illness.

'What has happened to me? What am I like this now? Why am I no longer as capable as I used to be? Why am I so slow when I want to bake or cook?' I know I was capable of doing many things when I was younger, but now, I'm slowing down in everything that I do.

(Female patient in her 60s)

\section{Continuing pleasure of the table $(n=12)$}

In days filled with exhausting patient role-related routines (such as trips to the hospital), uncertainty and declining health, the simple pleasure of a favourite meal can be an empowering source of dignity, comfort and normalcy.

I like to eat, until now. That's why, even this morning I went to Geylang [Singaporean suburb] to makan [Malay: To eat]. Despite not feeling too good, my appetite not so good as well, but I try to eat. (Female patient in her 50s)

The establishing of this smallest unit of attainable pleasure also aids family members in achieving a sense of ordinariness and care expression. Family members who accompany patients for their treatments and hospital appointments often turn them into food events.

...then after his medical check-up we always tend to think where we want to go makan because he loves food. I would prefer to go out with him now; whatever he wants to eat, when we are still able to walk...we take a cab then we go and makan. And we will hold hands; like this! (Female caregiver in her 70s)

\section{Food becoming lineage $(n=17)$}

The current major theme enunciates the continuing transformation of participants' food identity; when considered holistically, alchemises into social and personal legacies and wisdom extending both into the past as well as the future. The subthemes of (7) kitchen heritage, (8) kitchen legacy, and (9) kitchen wisdom observe this.

Kitchen heritage $(n=10)$

Participants forwarded their deep-rooted food identities within their larger cultural backgrounds. This process 
often elicited pride and feelings of generational continuity, tying in closely with tradition and ancestry.

My husband is Jawanese too; Padangese Indonesian. His mother used to sell Padangese rice. Her restaurant used to be packed during lunchtime. I learned from her and her recipes... ayam balado [Indonesian Spicy Fried Chicken]. He loves ikan balado [Indonesian Spicy Fried Fish], terong balado [Spicy Eggplant] and such. (Female patient in her 60s)

The ethnic identity of participants was celebrated in this manner, often converging closely to periods of traditional festivities that allowed them to reconnect to their heritage and ancestry.

My maternal grandmother was an amazing woman and she sold different pastries throughout the year; she sold sesame balls in March where people would offer them to their late ancestors [during Qingming festival (Tomb-Sweeping day)], followed by food offering to the Gods in April, rice dumplings in May [in commemoration of the Dragon Boat Festival], mooncakes in July and August, and finally roasted pork in October. (Male patient in his 80s)

\section{Kitchen legacy $(n=9)$}

Participants were also cognisant of their personal food legacies; what they had carefully and dutifully constructed over the course of a lifetime in and around the kitchen.

I don't make them [referring to her traditional pastries] anymore. In the past, I would make them by myself using good ingredients and they were delicious. The dishes and snacks that you buy from shops these days do not taste good. Homemade food is especially flavorful and fragrant. You have never tried it, hence you do not know how (good) it tastes. Food tastes better when it is homemade. There's a special taste to it (which resembles) the familiarity of grandma's cooking. (Male patient in his 60s)

Other than a source of personal pride and distinction, participants' legacies were also social celebrations; with families intimately involved as patrons, witnesses and guardians.

She's known for quite a lot of dishes... The entire family loves to eat popiah [savory spring roll]. When she cooks it, we ask everyone to come home to have it. It's not the usual Hakka version, it's the Hokkien version [Chinese dialect groups]. It's really tasty. She'd always complain that it's a lot of work, and that she's not going to cook it the next time, but she still does it. (Female caregiver in her 20s)

\section{Kitchen wisdom $(\mathrm{n}=14)$}

Participants viewed food experiences as valuable mediums for imparting lessons and wisdom, both within the kitchen and without. Family members can directly benefit from the knowledge handed down to them.

Culinary arts is not just the act of cooking and eating what you have cooked. It also involves grocery shopping, where you have to choose suitable ingredients such as a particular part of the fish or meat. It is not an easy as it sounds, especially for me as I am new to it. You have to learn from someone, by following them and observing what they choose to buy. It also involves planning a menu! (Female caregiver in her 40s)

Food is often used as a metaphor to eloquently instruct, inform and muse about life with all its intricacies and peculiarities.

Ah, but sometimes, we have to compromise and make a dish that everyone can eat...then it all comes down to whether you eat more or eat less of it. (Female patient in her 70s)

\section{Compassionate nourishment $(\mathrm{n}=\mathbf{2 1})$}

The final major theme in the study does not run linear to the chronos time observed among the others, instead weaving between all other themes and being present at every juncture of participants' lives. Food within the collectivistic Asian context is parallel to care provision, holding symbolic and practical meaning. The subthemes of (10) have you eaten?, (11) labour and love, and (12) the table to bond highlight this.

Have you eaten? $(n=17)$

The query of having had a meal is observed in various languages and dialects. It is perhaps the most conventional expression of empathic concern for well-being in Singapore, holding much nuance and undertones. This is often seen as a means of providing practical and symbolic care.

What do I like most about him (referring to patient)? I like when he would talk about wanting to bring us out to eat. He loves talking about where to eat. 'Where should we go? What would you like to eat?', he would ask. What I like the most is that he cares for the family. (Female caregiver in her 50s)

The expression is not seen as merely a polite or flippant greeting. A negative response to the query often begins a series of food-related activities that leads to providing for the individual who hasn't had a meal.

The memory with the deepest impression? My mum always worries that we will be hungry. During my growing years, she would always give me two dollars, saying, 'Hey, quickly go and eat something. During your growing years you shouldn't go hungry.' When I was a student, there were times when it would be late in the evening, and I would not have had a meal yet. I would call my mother and ask her if there was any food ready to eat at home. She would say, 'Yes, there 
is a lot of food! Hurry home so you can eat!' When I got home, I realized, 'But Mum, there is no food on the table. Why did you say there was food ready?' She replied, 'There will be food once I cook!' (Male caregiver in his $50 \mathrm{~s}$ )

\section{Labour and love $(n=17)$}

Food preparation is rarely an easy process. It is often time consuming and physically demanding. Participants enunciate this aspect of cooking as a true labour of love.

When my children were younger and staying with me, I could cook all day long in the kitchen and not feel tired at all. I wanted to feed them well, feed them with delicious food; and that makes me happy. People often say, 'When we cook, we must cook with a loving heart, but never with an angry mind.' (Female patient in her 60s)

With the onset of illness, patient participants also showed appreciation for the continuing effort that family members made with regard to food preparation, which often required some innovation due to nutritional limitations.

Everyday, she tries to have a different menu, especially when I'm sick. She's thinking of different food, and everyday she's asking me, just to be able to satisfy my palate. I'm slowly beginning to enjoy and taste those food. Coming back to it. She can cook all the different type of food. She also likes to make certain type of drinks. A mixture of drinks with avocado and all that, in a concoction...she likes to experiment on me! (Male patient in his 70s)

\section{The table to bond $(\mathrm{n}=18)$}

The final subtheme captures the multifaceted social component of food experiences within the lives of participants. These events showcase the authority of food as a means of bonding and a platform of familial continuity.

I do not ask for anything, and they (daughters) don't need to eat sumptuous meals; as long as we are eating together, we are very happy. Abalone will fill your stomach, just as salted vegetable will, right? I do not ask for much, just enough to fill the stomach, as long as we are happy together, I am content. (Male patient in his $60 \mathrm{~s}$ )

Participants also enunciated how stressful issues fell away when families bonded over a meal, showcasing the table to be a place of quiet dignity, solace and restfulness in times of turmoil and instability.

Sometimes we go to Changi Beach. Just sit down, buy some food and eat...that time when the children were small. Sometimes they see an ice-cream seller, I would just tell them; 'Take the money and go and buy.' We'll sit down, eat and be happy. I don't want to think about the stressors that I have. (Male patient in his 50s)

\section{DISCUSSION}

To the knowledge of the author, this is the first study that addresses the food-related identity, food's continuing role and food experiences (past, present and future) of dying individuals and their families within the Singaporean context. Though no specific food-centric queries were included in the FDI battery of questions, rich food-based responses occurred organically in response to various probes into participants' lives; emphasising, once again, the fundamental significance of nutritional assimilation within the culture. Findings indicate that the food voice of individuals at the end of life is resonant with vibrancy and tenor; alluding to such themes as personhood, survival, lineage and compassionate care. The FLiP model showcases the complex interplay of these themes and observes the linearity and changing nature of food at the end of life, for patients as well as familial caregivers. It was observed that the onset of terminal illness seemed to act as a prism with regard to patient participants' relationship to food, allowing multifaceted nuances to now come to light. Food identities became more solidified; memories both positive and negative were now appreciated with greater watchfulness through food-based reminiscences. The current place of food in their lives was also enunciated, allowing participants a psychosocial anchor in a period of turmoil and liminality. Musings on ancestral traditions and heritage as well sanctioned the creation of a curated platform for continuing food legacies and collated wisdom. These effects also extended in part to the family caregivers present during the dyadic interview process, allowing them to also consider their food voices, and how it harmonised with those of their charges. As seen by the responses of family caregiver participants, one's food voice is socially learnt as well as independently developed through personal experiences. Moreover, these food voices are also observed to facilitate some key constitutions of dignity, such as those alluded by Ho $e t a l,{ }^{31}$ especially in the thematic forms of 'Family Connectedness' and 'Filial Compassion' posited by the authors. This is perhaps best paralleled by the current study's major theme of 'Compassionate Nourishment', which encompasses these concepts.

Though the FLiP model was constructed with the responses of Singaporean participants, it is expected to demonstrate generalisability to other Asian communities and diasporas. This is in no small part due to the unique cultural overture that Singaporeans exhibit, showcasing ties and roots extending not merely into a collective national identity, but also into respective ethnic mainlands.

\section{Clinical implications}

Chapman and Maclean ${ }^{37}$ posit how the roles and meanings of food can foster insight and understanding to 
enhance practice effectiveness. In this vein, there are numerous clinical implications for the application of the findings presented in this work, both at institutional and industry levels.

As observed, the FLiP model showcased the often silenced and ignored food voice of dying patients and their family members. Employing the model as a frame of reference, empirical food-based clinical interventions can be developed to address a range of psychosociospiritual issues for these populations. Incorporation of the model into processes of narrative, reminiscence and logotherapeutic facilitation can aid focus on larger objectives, such as enhancing dignity, encouraging meaning-making and legacy creation as well as promoting continuing bonds through a food-based platform of open social communication.

Running parallel to the enunciated aims of the FDI developed by Ho $e t a l,{ }^{32}$ possible iterations can incorporate the FLiP model. The familial cocreation of a legacy cookbook (a 'FLiP Book', perhaps) can be one such example. Legacy activities have been demonstrated to improve social interaction and communication between patients in palliation and their families as well as reduce end-of-life distress. ${ }^{38}$ Such an intervention can borrow from the FLiP model to develop a set of protocol questions that elicit the various aspects of participants' food voice. Patients and families may come together to coauthor a record filled with curated recipes; closely guarded heritage secrets, favourite family meals, modern gastronomic discoveries, and so forth. The project can be documented with pictures, photographs, quotes and nuggets of crystallised kitchen wisdom, and bequeathed to families as a symbolic gesture continuation. After bereavement, this culinary journal will play the part of an heirloom; providing an endearing means of continuing bonds for immediate family, and an informative sociohistoric manuscript for later generation kin. This and similar culinary grief interventions may be informed by the study's results.

The current findings also hold important implications for industry providers of end-of-life nutritional supplements and options. The objective of nutritional support for palliation should always be increasing quality of life through comfort, symptom relief and enjoyment of food ${ }^{39}$ However, taste is often the first variable to fall to the wayside in attempts to ensure complete nutritional care. Routine ingestion of such products often leads to boredom and taste aversion, making food events a chore rather than ones looked forward to. Singaporean nursing homes are beginning to import gourmet meals for seniors from countries with standing nutritional research and preparation technologies such as $\operatorname{Japan}^{40}$; though this might pave the way for start-ups and local manufacturers to consider entering the market, breaking into palliative nutrition might be a daunting task, in part due to death aversion and superstitious taboo within the country.

The current flavoured supplements in the industry are often dismally monochrome when compared with the colourful taste experiences patients have been used to.
As such, industry partners may diversify existing flavours, which themselves are not often employed in Asian cooking (such as vanilla, strawberry and chocolate), to include the nuances seen in traditional and multicultural cuisine. Some examples might be 'Bandung' (rose milk), 'Kaya' (coconut jam) or 'Gula Melaka' (palm sugar); simple flavours but nonetheless rich in nostalgic meaning for many Singaporeans. Family caregivers as well might be comforted with the thought that nutritional assimilation at this juncture might still be a source of pleasure for their loved one.

\section{Limitations and future directions}

Though the current study is a novel undertaking with the generated FLiP model enunciating the role of food experiences for palliative patients and their families in the country, several limitations are observed. The first is that though the nature of the original study's semistructured interview process allowed for much leeway in addressing food-related concerns, such queries were not part of the standardised protocol, which focused on achieving other primary objectives. The research team, as such, did not have the opportunity to hear the food voices of all participants. Future application of the model may lead to its further reiteration, allowing for increased nuance. Moreover, due to inherent sampling issues, certain racial demographics were not represented in the study, most notably Tamil, Eurasian and other minority ethnic groups. As future work with regard to the FLiP model is continued, it is hoped that individuals from these groups would also be able to share their stories, voice and food experiences.

The FLiP model holds much cross-cultural promise were it to be extended to communities in the West; as food-related experiences over the life course might naturally differ from individuals living in Asian societies. Such prospective cross-cultural studies may also allude to the presence of a universal food voice for individuals, with undertones spanning across all cultures and lifestyles.

\section{CONCLUSION}

Like death, food and all its surrounding function, experiences, integrations and components remains one of the few truly ubiquitous influences that we share as human beings. We develop a food voice from birth, learn its tone and timbre and allow it to speak for us as a form of our own extended identity (both personal and sociocultural). It is a source of kinship and comfort, self-definition and empowerment that spans across the breadth of our lives. Most importantly, perhaps, it remains a rejuvenating wellspring for dignity, even through (and especially at) the final steps of our mortal journey.

Acknowledgements The authors would like to extend their gratitude to the patients and families who allowed them to be privy to their resonant and resplendent food voices. They would also like to thank Mr Chan Kin Nam for his work in the aesthetic design of the Food for Life and Palliation (FLiP) model as well as Ms Oindrila Dutta, Ms Shannon Goh and Ms Thurga Rajen for their continued support. 
Contributors PVP, GTH, PYC, CXL and HAHY conceived the design of the study and were involved in data collection. PVP, GTH, PYC and CXL transcribed and analysed the data collected, with critical input from HAHY. All authors agreed upon the final theme generation. PVP drafted this version of the manuscript with critical review and input from the four other authors. All authors have read and given approval for this version.

Funding The study was funded by the Singapore Ministry of Education (MoE) Academic Research Fund (AcRF) Tier 2 Fund (Ref: MOE-T2-1-061) and the Lien Foundation Special Grant.

Disclaimer The funders played no role in study design, collection, analysis or interpretation of data, or preparation of manuscripts.

Competing interests None declared.

Patient and public involvement Patients and/or the public were not involved in the design, or conduct, or reporting, or dissemination plans of this research.

Patient consent for publication Not required.

Ethics approval The participant informed consent procedure was conducted according to specifications of the researchers' host ethical review board, Nanyang Technological University's Institutional Review Board, from which approval of the study (IRB-2017-02-019) was obtained.

Provenance and peer review Not commissioned; externally peer reviewed.

Data availability statement All data relevant to the study are included in the article or uploaded as supplementary information. The data included in the study, namely qualitative quotes from participants, have all been deidentified.

Open access This is an open access article distributed in accordance with the Creative Commons Attribution Non Commercial (CC BY-NC 4.0) license, which permits others to distribute, remix, adapt, build upon this work non-commercially, and license their derivative works on different terms, provided the original work is properly cited, appropriate credit is given, any changes made indicated, and the use is non-commercial. See: http://creativecommons.org/licenses/by-nc/4.0/.

\section{ORCID iDs}

Paul Victor Patinadan http://orcid.org/0000-0003-0912-6673

Andy Hau Yan Ho http://orcid.org/0000-0003-0373-7043

\section{REFERENCES}

1 Connelly RJ. The sentiment argument for artificial feeding of the dying. Omega 1990;20:229-37.

2 Conner M, Armitage CJ. Social psychological models of food choice. In: The Psychology of Food Choice. Biddles Ltd: King's Lynn, 2006: 41-57.

3 Lupton D. Food, the body and the self. California: SAGE Publications, 1996.

4 Gullestad SE. The personal myth as a clinical concept. Int J Psychoanal 1995;76 (Pt 6:1155-66.

5 DeVault ML. Feeding the family: the social organization of caring as gendered work. Chicago: University of Chicago Press, 1994.

6 Bugge A. Cooking-As identity work. Proceedings of the 6th conference of the European sociological association; 2003 SEP 2326; Murcia, Spain. 2003. France: European Sociological Association.

7 Blumer H. Symbolic Interactionism: Perspective and Method. California: University of California Press, 1986.

8 Hauck-Lawson AS. When food is the voice: a case study of a Polish-American woman. Journal for the Study of Food and Society 1998;2:21-8

9 Barr J, Schumacher G. Using focus groups to determine what constitutes quality of life in clients receiving medical nutrition therapy: first steps in the development of a nutrition quality-of-life survey. J Am Diet Assoc 2003;103:844-51.

10 Kumari S, Sahu C. Food habits and its Socio-Cultural values among the Tribals of Jharkhand and Hindus of Bihar. Asian Man 2015;9:87-91.

11 Long LM. Learning to listen to the food voice: recipes as expressions of identity and carriers of memory. Food, Culture \& Society 2004; 7:118-22.

12 Counihan C, Van Esterik P, eds. Food and culture: A reader. London: Routledge, 2012.

13 Harris-Shapiro C. Bloody shankbones and braided bread: the food voice and the fashioning of American Jewish identities. Food and Foodways 2006;14:67-90.
14 Einat T, Davidian M. 'There is no sincerer love than the love of food' (George Bernard Shaw, 1903): The meaning of food and its uses in prison subculture. Eur J Criminol 2019;16:127-46.

15 Catherine Henderson J, Henderson JC. Food and culture: in search of a Singapore cuisine. Br Food J 2014;116:904-17.

16 Tan CB. Nyonya cuisine: Chinese, non-Chinese and the making of a famous cuisine in Southeast Asia. In: Cheung SCH, Tan CB, eds. Food and foodways in Asia: resource, tradition and cooking. New York: Routledge, 2009: 171-82.

17 Singapore Tourism Board. Makan delights: an insider's guide to Singapore's unique flavours. Singapore: Singapore Tourism Board, 2004.

18 Jay BN. Malaysia v Singapore: 'Nasi lemak burger' battle spices up, myBurgerLab throws down gauntlet. New Straits Times, 2017. Available: https://www.nst.com.my/news/nation/2017/08/263454/ malaysia-v-singapore-nasi-lemak-burger-battle-spices-myburgerlabthrows

19 Henderson JC. Cooked food Hawking and its management: the case of Singapore. Tourism Review International 2010;14:201-13.

20 Suen WH. A taste of the past: historically themed restaurants and social memory in Singapore. In: Cheung SCH, Tan CB, eds. Food and foodways in Asia: resource, tradition and cooking. New York: Routledge, 2009: 127-40.

21 Krishna LK, Poulose J, Goh C. Artificial hydration at the end of life in an oncology ward in Singapore. Indian J Palliat Care 2010;16:165-73.

22 Quill TE, Lo B, Brock DW. Palliative options of last resort: a comparison of voluntarily stopping eating and drinking, terminal sedation, physician-assisted suicide, and voluntary active euthanasia. In: Birnbacher D, Dahl E, eds. Giving death a helping hand: physician-assisted suicide and public policy: an international perspective. Dordrecht: Springer, 2008: 49-64.

23 Gruenewald DA, Eating VS. Voluntarily stopping eating and drinking: a practical approach for long-term care facilities. $J$ Palliat Med 2018:21:1214-20.

24 Hopkinson J, Corner J. Helping patients with advanced cancer live with concerns about eating: a challenge for palliative care professionals. J Pain Symptom Manage 2006;31:293-305.

25 Wong V, Krishna L. The meaning of food amongst terminally ill Chinese patients and families in Singapore. JMED Research 2014;2014:1-8.

26 Chai HZ, Krishna LKR, Wong VHM. Feeding: what it means to patients and caregivers and how these views influence singaporean chinese caregivers' decisions to continue feeding at the end of life. American Journal of Hospice and Palliative Medicine ${ }^{\circledR}$ 2013;31:166-71.

27 Kaplan AR. Ethnic foodways in everyday life: creativity and change among contemporary Minnesotans [dissertation. Pennsylvania: University of Pennsylvania, 1984.

28 Chochinov HM. Dignity-conserving care-a new model for palliative care: helping the patient feel valued. JAMA 2002;287:2253-60.

29 Edwards A, Pang N, Shiu V, et al. The understanding of spirituality and the potential role of spiritual care in end-of-life and palliative care: a meta-study of qualitative research. Palliat Med 2010;24:753-70.

30 Wilson KG, Graham ID, Viola RA, et al. Structured interview assessment of symptoms and concerns in palliative care. Can $J$ Psychiatry 2004;49:350-8.

$31 \mathrm{AHY} \mathrm{H}$, Chan CLW, Chow AWM. Filial Piety and dignity in end of life caregiving: lived experience of Chinese families facing terminal illness. Washington DC: The Gerontology Society of America, 2014.

$32 \mathrm{Ho}$ AHY, Car J, Ho M-HR, et al. A novel family dignity intervention (Fdl) for enhancing and informing holistic palliative care in Asia: study protocol for a randomized controlled trial. Trials 2017;18:587.

33 O'Brien BC, Harris IB, Beckman TJ, et al. Standards for reporting qualitative research. Academic Medicine 2014;89:1245-51.

34 Srivastava A, Thompson SB. Framework analysis: a qualitative methodology for applied policy research. JOAAG 2009;4:72-9.

35 Guba EG. ERIC/ECTJ annual review paper: criteria for assessing the Trustworthiness of naturalistic inquiries. A Journal of Theory, Research, and Development 1981;29:75-91.

36 Shenton AK. Strategies for ensuring trustworthiness in qualitative research projects. Education for Information 2004;22:63-75.

37 Chapman G, Maclean H. "Junk food" and "healthy food": meanings of food in adolescent women's culture. J Nutr Educ 1993;25:108-13.

38 Allen RS, Hilgeman MM, Ege MA, et al. Legacy activities as interventions approaching the end of life. J Palliat Med 2008;11:1029-38.

39 Acreman S. Nutrition in palliative care. Br J Community Nurs 2009;14:427-31.

40 Tai J. Elder-friendly meals, anyone? the Straits times, 2017. Available: https://www.straitstimes.com/singapore/safe-treats-for-seniors 